\title{
Capulavirus and Grablovirus: two new genera in the family Geminiviridae
}

\author{
Arvind Varsani ${ }^{1,2}{ }^{(10} \cdot$ Philippe Roumagnac $^{3} \cdot$ Marc Fuchs $^{4} \cdot$ Jesús Navas-Castillo $^{5}$. \\ Enrique Moriones $^{5} \cdot$ Ali Idris $^{6} \cdot$ Rob W. Briddon $^{7} \cdot$ Rafael Rivera-Bustamante $^{8}$.

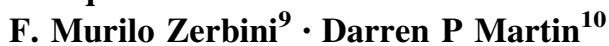

Received: 20 January 2017 / Accepted: 27 January 2017/Published online: 17 February 2017

(c) Springer-Verlag Wien 2017

\begin{abstract}
Geminiviruses are plant-infecting single-stranded DNA viruses that occur in most parts of the world. Currently, there are seven genera within the family Geminiviridae (Becurtovirus, Begomovirus, Curtovirus, Eragrovirus, Mastrevirus, Topocuvirus and Turncurtovirus). The rate of discovery of new geminiviruses has increased significantly over the last decade as a result of new molecular tools and approaches (rolling-circle amplification and deep sequencing) that allow for high-throughput workflows. Here, we report the establishment of two new genera: Capulavirus, with four new species (Alfalfa leaf curl virus, Euphorbia caput-medusae latent virus, French bean severe leaf curl virus and Plantago lanceolata latent virus), and Grablovirus, with one new species (Grapevine red blotch virus). The aphid species Aphis craccivora has been shown to be a vector for Alfalfa leaf curl virus, and
\end{abstract}

Arvind Varsani

arvind.varsani@asu.edu

$\square$ Darren P Martin

darrenpatrickmartin@gmail.com

1 The Biodesign Center for Fundamental and Applied Microbiomics, Center for Evolution and Medicine and School of Life Sciences, Arizona State University, Tempe 85287-5001, AZ, USA

2 Structural Biology Research Unit, Department of Clinical Laboratory Sciences, University of Cape Town, Cape Town 7701, South Africa

3 CIRAD-INRA-SupAgro, UMR BGPI, Campus International de Montferrier-Baillarguet, 34398 Montpellier Cedex-5, France

4 Section of Plant Pathology and Plant-Microbe Biology, School of Integrative Plant Science, Cornell University, New York State Agricultural Experiment Station, Geneva, NY 14456, USA the treehopper species Spissistilus festinus is the likely vector of Grapevine red blotch virus. In addition, two highly divergent groups of viruses found infecting citrus and mulberry plants have been assigned to the new species Citrus chlorotic dwarf associated virus and Mulberry mosaic dwarf associated virus, respectively. These species have been left unassigned to a genus by the ICTV because their particle morphology and insect vectors are unknown.

\section{Introduction}

The family Geminiviridae includes plant-infecting viruses with circular ssDNA genomes that are encapsidated in virions comprised of 22 pentameric capsomeres arranged in a $\sim 18$ - to $30-\mathrm{nm}$ twinned icosahedral (or geminate)

5 Instituto de Hortofruticultura Subtropical y Mediterránea "La Mayora”, Universidad de Málaga-Consejo Superior de Investigaciones Científicas (IHSM-UMA-CSIC), 29750 Algarrobo-Costa, Málaga, Spain

6 School of Plant Sciences, University of Arizona, Tucson, AZ 85721-0107, USA

7 National Institute for Biotechnology and Genetic Engineering (NIBGE), Faisalabad, Pakistan

8 Departamento de Ingeniería Genética, Centro de Investigación y de Estudios Avanzados del IPN (Cinvestav), Unidad Irapuato, 36821 Irapuato, GTO, Mexico

9 Dep. de Fitopatologia/Bioagro, Universidade Federal de Viçosa, Viçosa, Minas Gerais 36570-900, Brazil

10 Computational Biology Group, Institute of Infectious Diseases and Molecular Medicine, University of Cape Town, Cape Town 7925, South Africa 
configuration [7, 41]. Geminiviruses have a near-global distribution and infect both monocotyledonous and dicotyledonous plants. Geminiviruses are often responsible for serious yield losses in economically important crops, including tomato, maize, cotton, chickpea and cassava [25]. Symptoms of geminivirus infections can include foliar crinkling, curling, yellowing, stunting, mosaic and/or striations.

The Geminiviridae Study Group of the International Committee on Taxonomy of Viruses (ICTV) has provided a series of guidelines for the classification of viruses within the seven currently recognised genera of the family: $B e$ curtovirus, Begomovirus, Curtovirus, Eragrovirus, Mastrevirus, Topocuvirus and Turncurtovirus. The criteria include host range, insect vector, genome organisation and genome-wide pairwise sequence identities $[1,11,12,26,38,39]$.

Over the last decade, the development of new molecular tools such as rolling-circle amplification (RCA) and highthroughput sequencing have greatly facilitated the discovery of novel geminiviruses in a range of cultivated and noncultivated host species [29]. Accordingly, these techniques have accelerated the discovery of highly divergent geminivirus-like viruses. For some of these viruses, a large number of closely related full genome sequences have been determined. Analyses of these sequences (pairwise identities and phylogenetics), coupled with the identification of insect vectors and particle morphology, have allowed us to determine with great confidence that some of these divergent viruses should be classified as members of two new genera in the family Geminiviridae, which was approved by the Executive Committee of the ICTV:

1) Capulavirus, which will for now include four species, Alfalfa leaf curl virus, Euphorbia caputmedusae latent virus, French bean severe leaf curl virus and Plantago lanceolata latent virus $[5,6,30,36]$

2) Grablovirus, which will for now include one species, Grapevine red blotch virus [18, 28, 35]

In addition, two other species of highly divergent viruses that are closely related to geminiviruses have been accepted by the Executive Committee of the ICTV for inclusion in the family Geminiviridae and will remain unassigned to a genus, awaiting identification of the vector species and confirmation of particle morphology. These new species are:

1) Citrus chlorotic dwarf associated virus $[17,21]$

2) Mulberry mosaic dwarf associated virus $[23,24]$

Furthermore, recently, a single virus isolated from an apple tree in China (tentatively referred to as apple geminivirus; AGmV) [20] and 13 virus isolates from grapevine
Fig. 1 Genome organisation of viruses in the genera of the family Geminiviridae. Citrus chlorotic dwarf associated virus and Mulberry mosaic dwarf associated virus have been accepted by the Executive Committee of the International Committee on Taxonomy of Viruses (ICTV) as a species within the family Geminiviridae but have not been assigned to a genus. AGmV and GGVA have not yet been considered as representatives of a species by ICTV

in Hungary, Israel, Japan and South Korea (tentatively referred to as grapevine geminivirus A; GGVA) sharing $>97 \%$ pairwise identity have been discovered [2]. These have distinctly geminivirus-like genome organisations and are more closely related to members of some established geminivirus species than they are to citrus chlorotic dwarf associated virus $(\mathrm{CCDaV})$ and mulberry mosaic dwarf associated virus (MMCaV). The taxonomic assignment of AGmV and GGVA still needs to be discussed by the ICTV.

Whereas the arrangements of genes and intergenic regions in the genomes of curtoviruses, topocuviruses, turncurtoviruses, AGmV, GGVA and genomes/DNA A components of begomoviruses are all very similar, the becurtoviruses, capulaviruses, eragroviruses, grabloviruses and mastreviruses all have distinctly unique genome organisations (Fig. 1). Furthermore, the genome organisation of $\mathrm{CCDaV}$ is also apparently unique [21]. Particularly noteworthy in the CCDaV genome (3640 nt) is the $~ 921$ nt-long virion-sense ORF, V3, which results in the $\mathrm{CCDaV}$ genome being 600-800 nt larger than those of the other known monopartite geminiviruses (Fig. 1).

Although the genomes of the known geminiviruses can have up to eight genes, only two of them, the replicationassociated protein gene (rep) and the coat protein gene $(c p)$ are obviously conserved across viruses in all of the genera, whereas the replication enhancer gene (ren), symptom determinant gene $(s d)$ and silencing suppressor gene $(s s)$ homologues are found in begomoviruses, curtoviruses, topocuviruses and turncurtoviruses (Fig. 1), and transcription activator gene (trap) homologues are additionally found in eragroviruses (Fig. 1). The genomes of viruses in all of the established genera also have either proven or putative movement protein genes ( $m p$ ), which, in the monopartite members of the family, are immediately upstream of $c p$. It is currently unknown, however, if these genes in viruses from different genera have a common evolutionary origin, because the amino acid sequences that they encode have such low degrees of similarity that it is not possible to conclude that they are homologous.

The genomes of becurtoviruses, capulaviruses, grabloviruses, eragroviruses, mastreviruses, and $\mathrm{CCDaVs}$ all have two intergenic regions (Fig. 1). In general, the longer of these is referred to as the long intergenic region (LIR) and contains a conserved nonanucleotide within a hairpin structure that forms the origin of virion-strand replication $[3,22]$. Similarly, the shorter intergenic region is referred 

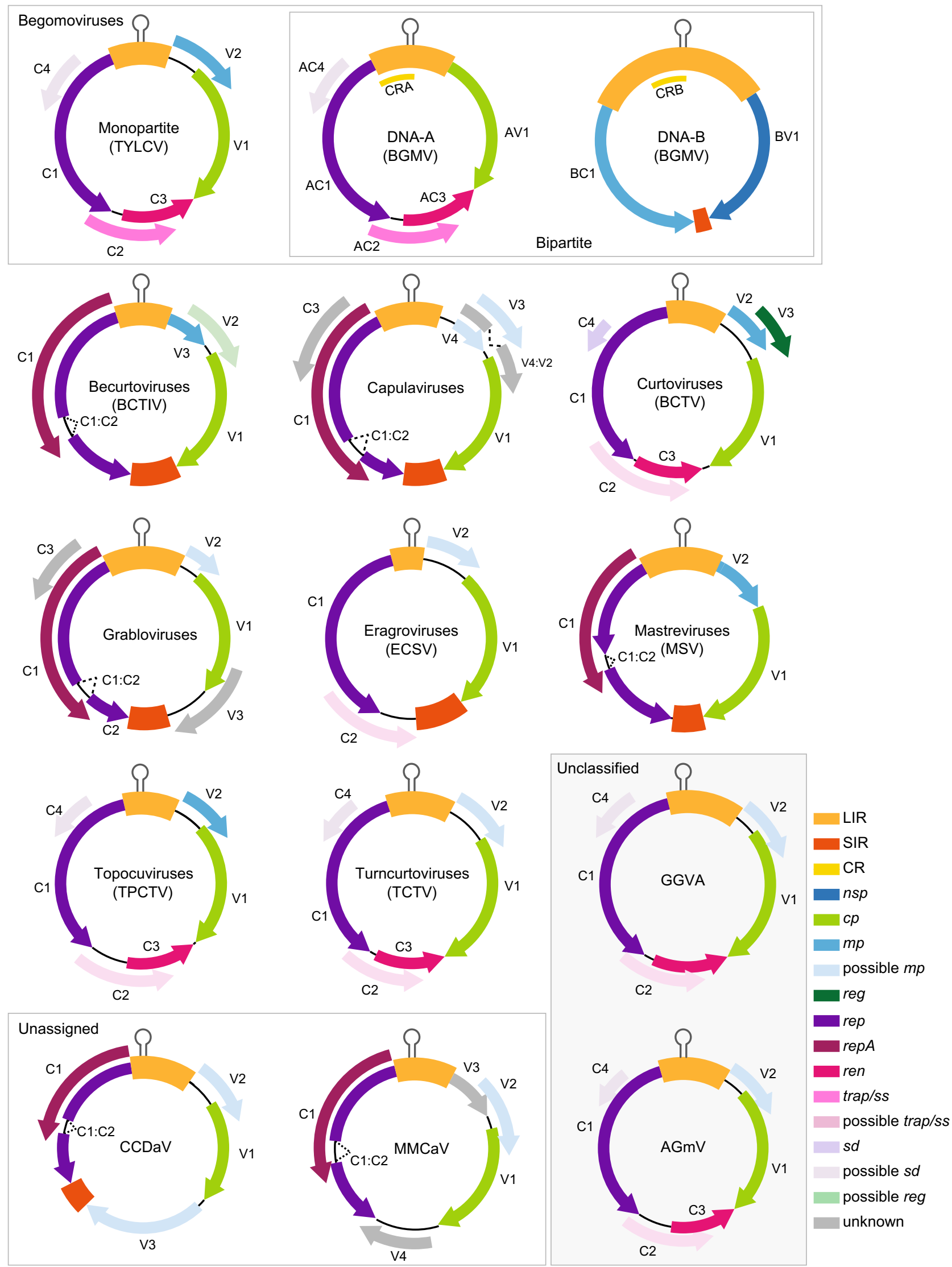
to as the short intergenic region (SIR) and contains transcription termination signals and, for mastreviruses at least, the origin of complementary-strand replication.

Introns are present in several geminivirus genes. Rep and RepA proteins in becurtoviruses, capulaviruses, grabloviruses, mastreviruses, $\mathrm{MMCaV}$ and $\mathrm{CCDaV}$ are either proven to be, or inferred to be, expressed from alternatively spliced complementary-sense transcripts [8, 13, 40] (Fig. 1). Further, an intron occurs in the $m p$ of mastreviruses [40], and an intron has been inferred to occur in the $m p$ of the capulavirus EcmLV (Fig. 1) [5].

Recombination has played a significant role in the evolution of geminiviruses, and it can therefore be difficult to accurately infer the evolutionary relationships of viruses in different genera. Whereas non-homologous recombination has potentially contributed to the loss or gain of large genome regions in particular genera, homologous recombination has also likely contributed to the exchange of genome regions between viruses in different genera $[6,9,31,33]$.

Nonetheless, we inferred the approximate genome-wide evolutionary relationships between representative members of the various established geminivirus genera, $\mathrm{CCDaV}$, $\mathrm{MMCaV}, \mathrm{AGmV}$ and GGVA (Fig. 1). The full genome sequences of these representative viruses were aligned using MUSCLE [15] and used to infer a neighbor-joining phylogenetic tree with the Jukes-Cantor nucleotide substitution model and 1000 bootstrap replicates. Branches with $<60 \%$ support were collapsed using TreeGraph2 [34], and the tree was rooted at the midpoint (Fig. 2). From this phylogenetic tree, it is apparent that the capulaviruses and grabloviruses are closely related to one another and that $\mathrm{CCDaV}$ and $\mathrm{MMCaV}$ are closely related to one another.

We also analysed the evolutionary relationships of the inferred CP and Rep amino acid sequences of the same set of representative geminiviruses. The $\mathrm{CP}$ and Rep sequence datasets were aligned using MUSCLE [15] and used to infer maximum-likelihood phylogenetic trees using PHYML3.0 [16], applying the $\mathrm{WAG}+\mathrm{I}+\mathrm{G}$ and $\mathrm{LG}+\mathrm{I}+\mathrm{G}$ substitution model, respectively (selected as the best-fit models by ProtTest [14]; Fig. 2). Branch support in these trees was determined using approximate likelihood ratio tests (aLRT). The Rep phylogenetic tree was rooted with sequences from the family Genomoviridae [19], whereas the $\mathrm{CP}$ tree was rooted at the midpoint. Branches with $<80 \%$ aLRT support were collapsed using TreeGraph2 [34]. Pairwise CP and Rep amino acid sequence identities were determined using SDT v1.2 [27] (Fig. 3).

Discordance in the phylogenetic placement of curtoviruses, becurtoviruses, topocuviruses, eragroviruses, turncurtoviruses and $\mathrm{CCDaV}$ in the $\mathrm{CP}$ and Rep phylogenetic trees likely reflects the fact that the most recent common ancestors of the known viruses in these genera are
Fig. 2 A. Unrooted neighbour-joining tree inferred from aligned fullgenome sequences of representative isolates from various genera in the family Geminiviridae. Numbers associated with branches indicate percentage bootstrap support for these branches (determined with 1000 bootstrap replicates). B. Maximum-likelihood phylogenetic tree (applying the $\mathrm{WAG}+\mathrm{I}+\mathrm{G}$ amino acid substitution model) inferred from aligned CP sequences of representative isolates from various genera in the family Geminiviridae. Numbers associate with branches indicate percentage aLRT support for these branches. The $\mathrm{CP}$ phylogenetic tree is rooted at the midpoint. Branches with less than $80 \%$ aLRT support have been collapsed. C. Maximum-likelihood phylogenetic tree (applying the $\mathrm{LG}+\mathrm{I}+\mathrm{G}$ amino acid substitution model) inferred from aligned Rep sequences of representative isolates from various genera in the family Geminiviridae. Numbers associated with branches indicate percentage aLRT support for these branches. The Rep phylogenetic tree is rooted with the Rep sequences of members of the family Genomoviridae (not included here). Branches with less than $80 \%$ aLRT support have been collapsed

possibly the products of inter-genus recombination events $[10,37]$. For example, the becurtovirus CPs are most closely related to those of curtoviruses, whereas the becurtovirus Reps are most closely related to those of $\mathrm{CCDaV}$ and MMCaV (Fig. 2 and Fig. 3).

\section{Capulavirus}

A group of closely related viruses isolated from Euphorbia caput-medusae (South Africa), Medicago sativa (France and Spain), Phaseolus vulgaris (India) and Plantago lanceolata (Finland) have been assigned to the new genus Capulavirus. The genus name Capulavirus was derived from the type member of the genus: euphorbia caput-medusae latent virus. As with viruses in the genera Mastrevirus and Becurtovirus, capulaviruses have two intergenic regions and express Rep from a spliced complementarystrand transcript. In common with begomoviruses and curtoviruses, they have a large complementary-sense ORF (C3) that is completely embedded within rep. A unique feature of capulavirus genomes is a complex arrangement of possible MP-encoding ORFs located in the 5'direction from $c p$ (Fig. 1). Two or more of these ORFs may constitute an intron-containing $m p$ (Fig. 1). Geminate particles have been observed in purified preparations of EcmLV by transmission electron microscopy [30]. Aphids of the species Aphis craccivora have been shown to transmit ALCV [30]. All known capulaviruses have the nonanucleotide motif "TAATATTAC" at their presumed origins of virionstrand replication.

An analysis of the distribution of pairwise identities (one minus Hamming distances of pairwise aligned sequences with pairwise deletion of gaps) of known capulavirus genomes using SDT v1.2 [27] $(\mathrm{n}=47$; Table 1) indicates that a pairwise-identity-based species demarcation criterion that would minimize conflicts (i.e., possible assignments of 
Genome

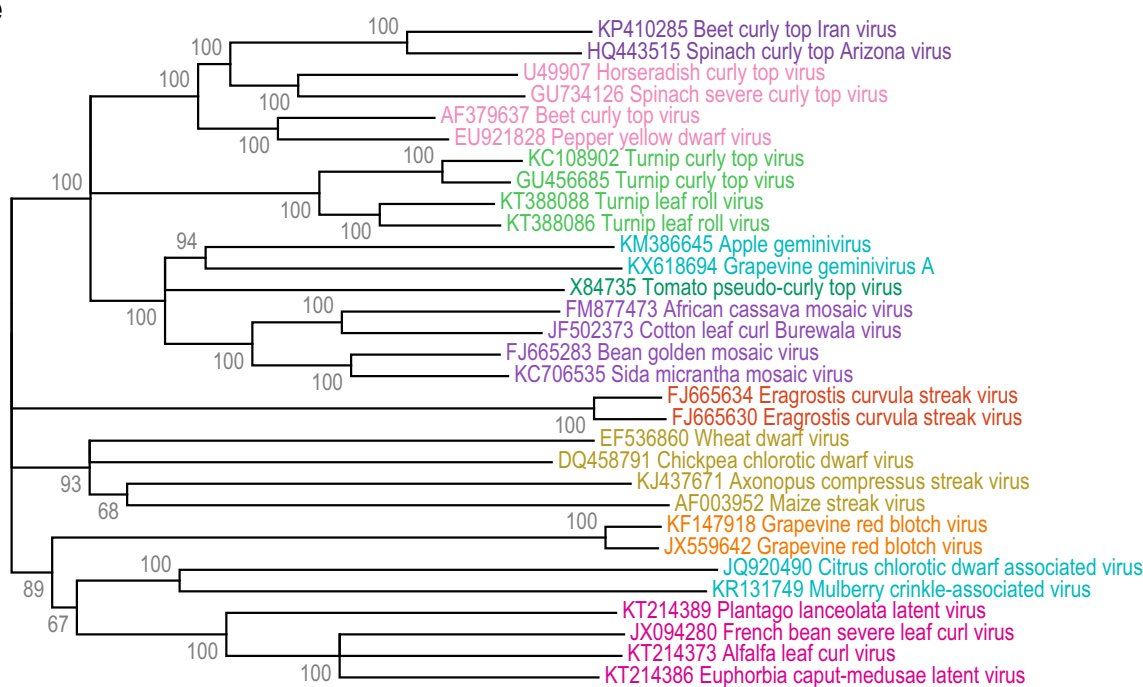

0.1 nucleotide substitutions per site

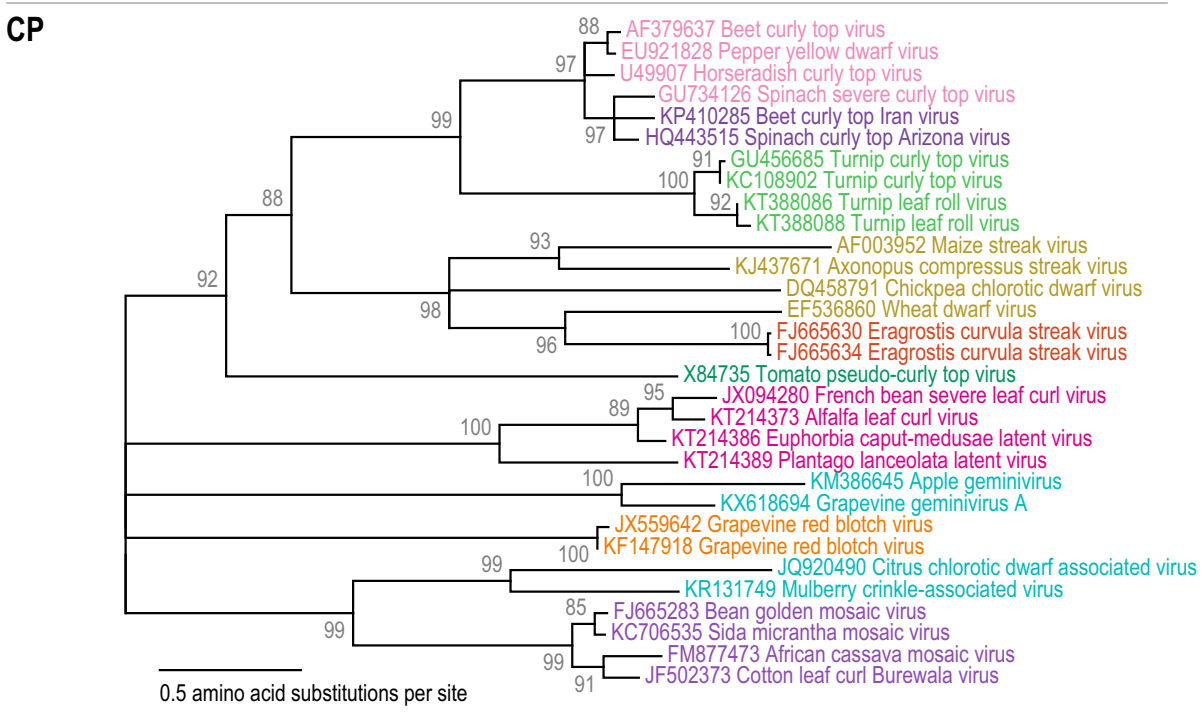

Rep

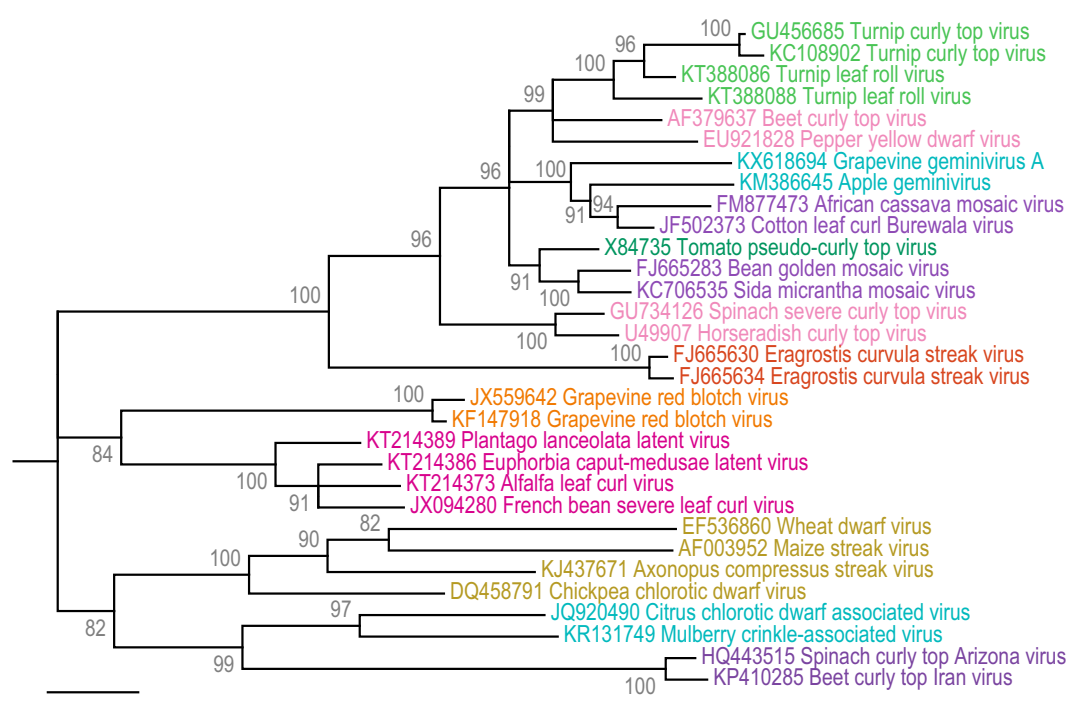

0.2 amino acid substitutions per site
Genera

I Becurtovirus

Curtovirus

Turncurtovirus

I unclassified

- Topocuvirus

Begomovirus

| Eragrovirus

Mastrevirus

I Grablovirus

I unclassified

Capulavirus

Curtovirus

I Becurtovirus

Turncurtovirus

Mastrevirus

Eragrovirus

- Topocuvirus

Capulavirus

| unclassified

I Grablovirus

unclassified

Begomovirus

Turncurtovirus

| Curtovirus

| unclassified

| Begomovirus

- Topocuvirus

| Begomovirus

| Curtovirus

I Eragrovirus

I Grablovirus

Capulavirus

Mastrevirus

| unclassified

I Becurtovirus 
individual isolates to two or more species) could be placed either in the 72 to $84 \%$ identity interval, or in the $87-94 \%$ interval (Fig. 4). Whereas a species demarcation threshold within the $87-94 \%$ range would yield five species, placing it within the $72-84 \%$ range would yield four species. In the case of a threshold within the $87-94 \%$ range, the alfalfa leaf curl virus (ALCV) sequences, which have all been isolated from alfalfa plants, would be split into two species. Given that there seems to be no good biological reason to split the ALCVs into two species, we have opted to tentatively place the species demarcation threshold in the $72-84 \%$ range. To bring the capulavirus species demarcation threshold in line with that of the genus Mastrevirus (the recognized genus of geminiviruses that the capulaviruses are most closely related to; Fig. 4) we have opted to tentatively select $78 \%$ as the pairwise identity value above which two sequences should be considered isolates of the same species. The four proposed capulavirus species to which the 47 known capulavirus full genome sequences (Table 1) have been assigned are Alfalfa leaf curl virus $(\mathrm{n}=26)$, Euphorbia caput-medusae latent virus $(\mathrm{n}=17)$, French bean severe leaf curl virus $(\mathrm{n}=2)$ and Plantago lanceolata latent virus $(\mathrm{n}=2)$. Based on pairwise identity comparisons, all isolates (ALCV; EcmLV; french bean severe leaf curl virus, FbSLCV; plantago lanceolata latent virus, PILV) within each of these species share between $63 \%$ and $73 \%$ genome-wide sequence identity with all isolates that have been assigned to other proposed capulavirus species (Fig. 2).

Regardless of whether the full-genome nucleotide sequence, the inferred Rep amino acid sequence, or the inferred CP amino acid sequence is considered, all of the viruses belonging to the proposed capulavirus species group with 100\% aLRT support with other proposed capulaviruses (Fig. 2). The viruses assigned to the genus Capulavirus share $<22 \%$ CP amino acid sequence identity and $<45 \%$ Rep amino acid sequence identity with viruses in other established genera of the family Geminiviridae (Fig. 3).

\section{Grablovirus}

A group of closely related viruses discovered infecting grapevines in Canada, South Korea and the USA have been assigned to the genus Grablovirus. The genus name is based on the name of the type member: grapevine red blotch virus (GRBV), the first and currently the only member of this genus [18]. These viruses have the virionstrand origin of replication nonanucleotide motif TAATATTAC and a unique genome arrangement (Fig. 1; Table 2). The natural vector is likely the three-cornered alfalfa treehopper (Spissistilus festinus Say) [4].
Analysis of the 27 known grablovirus full-genome sequences indicate that they all share $>91 \%$ genome-wide nucleotide sequence identity (Fig. 5) and are therefore all assigned to the species Grapevine red blotch virus. All of the GRBV isolates share $<45 \%$ Rep amino acid sequence identity with all viruses in other geminivirus genera (Fig. 3). Regardless of whether the full-genome nucleotide sequence, Rep amino acid sequence or CP amino acid is considered, the GRBV isolates cluster together with $100 \%$ aLRT support (Fig. 2).

In the absence of additional related sequences in the genus, we suggest that, based on the species demarcation criteria used for most other geminivirus genera, grablovirus isolates sharing $<80 \%$ genome-wide pairwise identity with members of accepted grablovirus species should be classified as members of distinct grablovirus species. This is a tentative species demarcation criterion that will need to be refined as more full-genome sequences of grabloviruses are determined.

\section{New geminivirus species that remain unassigned to a genus}

\section{Citrus chlorotic dwarf associated virus and Mulberry mosaic dwarf associated virus}

Two complete CCDaV genomes, isolated from citrus trees in Turkey (JQ920490) [21] and China (KF561253), and eight complete MMCaV genomes, isolated from mulberry bushes in China (KP303687, KP699128-KP699132, KP728254, KR131749) [23, 24], are clearly closely related to those of geminiviruses, based on both their geminiviruslike genome organization and the fact that their inferred Rep and CP amino acid sequences cluster phylogenetically with those of the known geminiviruses (Fig. 1 and Fig. 2). All known CCDaV and MMDaV isolates also have the nonanucleotide TAATATTAC, which is characteristic of the virion-strand origin of replication of the majority of geminiviruses.

The two CCDaV sequences share $99.5 \%$ genome-wide pairwise identity, whereas the eight MMDaV sequences share $>97 \%$ identity. The predicted Rep proteins of these $\mathrm{CCDaV}$ and $\mathrm{MMDaV}$ isolates share $\sim 58 \%$ amino acid sequence similarity with one another, but only $33-42 \%$ similarity with those of other geminiviruses (Fig. 3). Regardless of whether full genome nucleotide sequences, inferred Rep amino acid sequences, or inferred CP amino acid sequences are considered, the two proposed species group separately from all other geminiviruses, with $100 \%$ aLRT branch support (Fig. 2). 


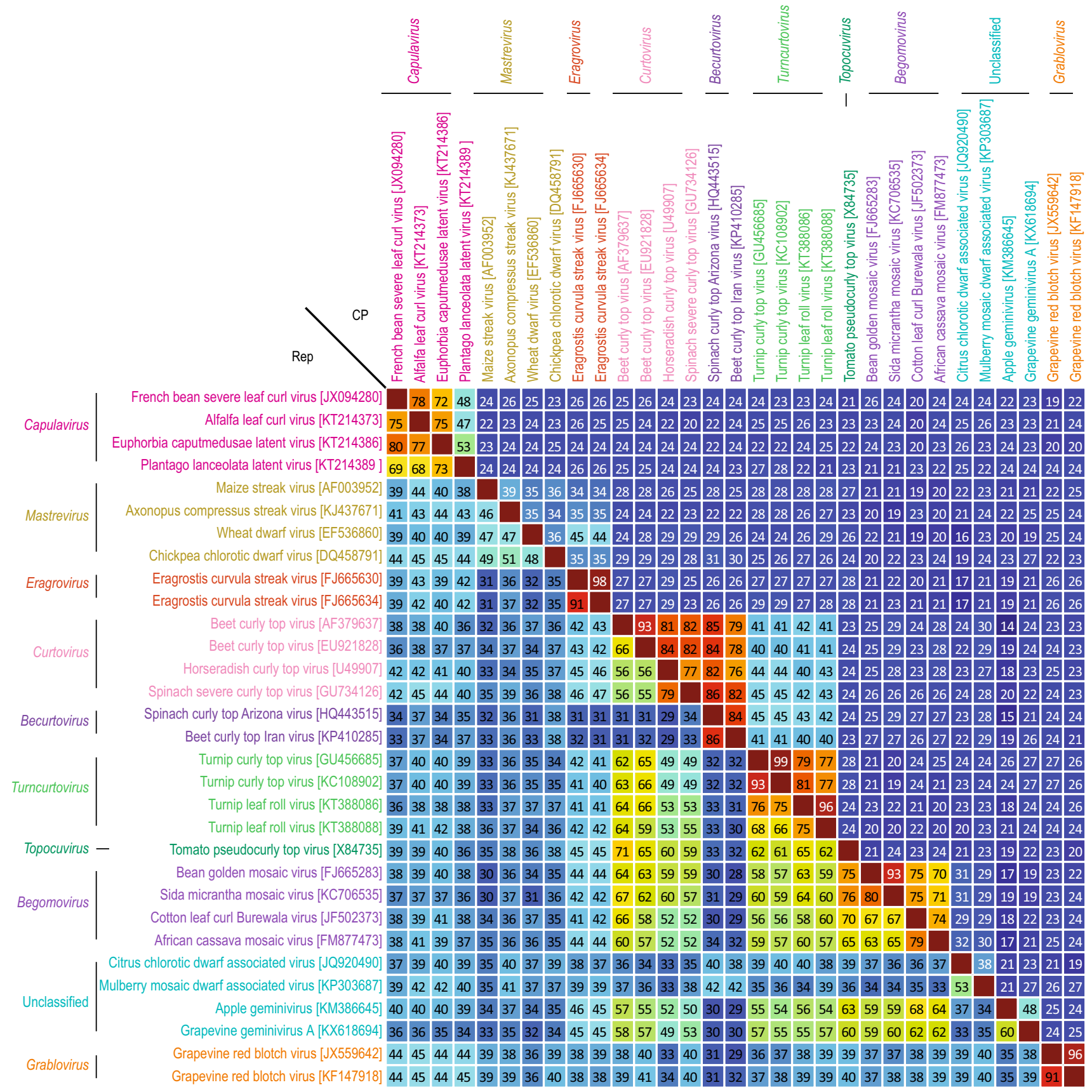

Pairwise identity (\%)

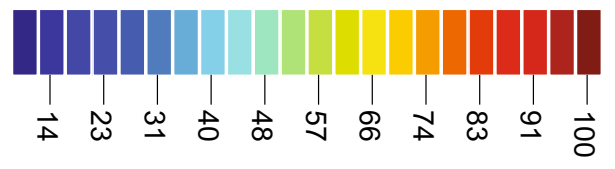

Fig. 3 Pairwise identities of the Rep and CP sequences of representative isolates from various genera in the family Geminiviridae as determined using SDT v1.2 (Muhire et al., 2014) 
Table 1 Details of virus isolates that have been assigned to the four proposed species within the genus Capulavirus

\begin{tabular}{|c|c|c|c|c|c|}
\hline Capulavirus & Accession no. & Virus acronym & Isolate & Country & Host \\
\hline \multirow[t]{27}{*}{ Alfalfa leaf curl virus } & KP732474 & ALCV & $44-1 \mathrm{E}$ & France & Medicago sativa \\
\hline & KT214350 & ALCV & TDV14_44-16 & France & Medicago sativa \\
\hline & KT214351 & ALCV & PB14_LUZ166 & France & Medicago sativa \\
\hline & KT214352 & ALCV & ASS14_Assas2 & France & Medicago sativa \\
\hline & KT214353 & ALCV & BON14_LUZ075 & France & Medicago sativa \\
\hline & KT214354 & ALCV & SSL14_Toul1 & France & Medicago sativa \\
\hline & KT214355 & ALCV & ALB14_LUZ147 & France & Medicago sativa \\
\hline & KT214356 & ALCV & ALB14_LUZ163 & France & Medicago sativa \\
\hline & KT214357 & ALCV & SSL14_Toul7 & France & Medicago sativa \\
\hline & KT214358 & ALCV & TDV12_48-2A & France & Medicago sativa \\
\hline & KT214359 & ALCV & PB14_LUZ184 & France & Medicago sativa \\
\hline & KT214360 & ALCV & ASS14_Assas1 & France & Medicago sativa \\
\hline & KT214361 & ALCV & VAU14_LUZ136 & France & Medicago sativa \\
\hline & KT214362 & ALCV & GAG14_LUZ193 & France & Medicago sativa \\
\hline & KT214363 & ALCV & PB14_LUZ182 & France & Medicago sativa \\
\hline & KT214364 & ALCV & ALB14_LUZ148 & France & Medicago sativa \\
\hline & KT214365 & ALCV & PB14_LUZ-GS4 & France & Medicago sativa \\
\hline & KT214366 & ALCV & ALB14_LUZ164 & France & Medicago sativa \\
\hline & KT214367 & ALCV & PB14_LUZ171 & France & Medicago sativa \\
\hline & KT214368 & ALCV & PB14_LUZ188 & France & Medicago sativa \\
\hline & KT214369 & ALCV & PB14_LUZ-GS6 & France & Medicago sativa \\
\hline & KT214370 & ALCV & BON14_LUZ076 & France & Medicago sativa \\
\hline & KT214371 & ALCV & PB14_LUZ165 & France & Medicago sativa \\
\hline & KT214372 & ALCV & PB14_LUZ178 & France & Medicago sativa \\
\hline & KT214373 & ALCV & VAU14_LUZ142 & France & Medicago sativa \\
\hline & KT214374 & ALCV & PB14_GS8 & France & Medicago sativa \\
\hline & KT214375 & ALCV & PB14_LUZ179 & France & Medicago sativa \\
\hline \multirow[t]{16}{*}{ Euphorbia caput-medusae latent virus } & HF921459 & EcmLV & Dar10 & South Africa & Euphorbia caput-medusae \\
\hline & HF921460 & EcmLV & Dar11 & South Africa & Euphorbia caput-medusae \\
\hline & HF921477 & EcmLV & Lap11 & South Africa & Euphorbia caput-medusae \\
\hline & KT214376 & EcmLV & DAR12_CM243 & South Africa & Euphorbia caput-medusae \\
\hline & KT214377 & EcmLV & DAR12_CM26 & South Africa & Euphorbia caput-medusae \\
\hline & KT214378 & EcmLV & DAR12_CM176 & South Africa & Euphorbia caput-medusae \\
\hline & KT214379 & EcmLV & DAR12_CM27 & South Africa & Euphorbia caput-medusae \\
\hline & KT214380 & EcmLV & DAR12_CM192 & South Africa & Euphorbia caput-medusae \\
\hline & KT214381 & EcmLV & DAR12_CM186 & South Africa & Euphorbia caput-medusae \\
\hline & KT214382 & EcmLV & DAR12_CM240 & South Africa & Euphorbia caput-medusae \\
\hline & KT214383 & EcmLV & DAR12_CM162 & South Africa & Euphorbia caput-medusae \\
\hline & KT214384 & EcmLV & PAT12_CM96 & South Africa & Euphorbia caput-medusae \\
\hline & KT214385 & EcmLV & PAT12_CM99 & South Africa & Euphorbia caput-medusae \\
\hline & KT214386 & EcmLV & PAT12_CM101 & South Africa & Euphorbia caput-medusae \\
\hline & KT214387 & EcmLV & DAR12_CM217 & South Africa & Euphorbia caput-medusae \\
\hline & KT214388 & EcmLV & DAR12_CM251 & South Africa & Euphorbia caput-medusae \\
\hline \multirow[t]{2}{*}{ French bean severe leaf curl virus } & JX094280 & FbSLCV & FbSLCV-1 & India & Phaseolus vulgaris \\
\hline & JX094281 & FbSLCV & FbSLCV-2 & India & Phaseolus vulgaris \\
\hline \multirow[t]{2}{*}{ Plantago lanceolata latent virus } & KT214389 & PILV & ALA13_P111 & Finland & Plantago lanceolata \\
\hline & KT214390 & PlLV & ALA13_Pl5 & Finland & Plantago lanceolata \\
\hline
\end{tabular}



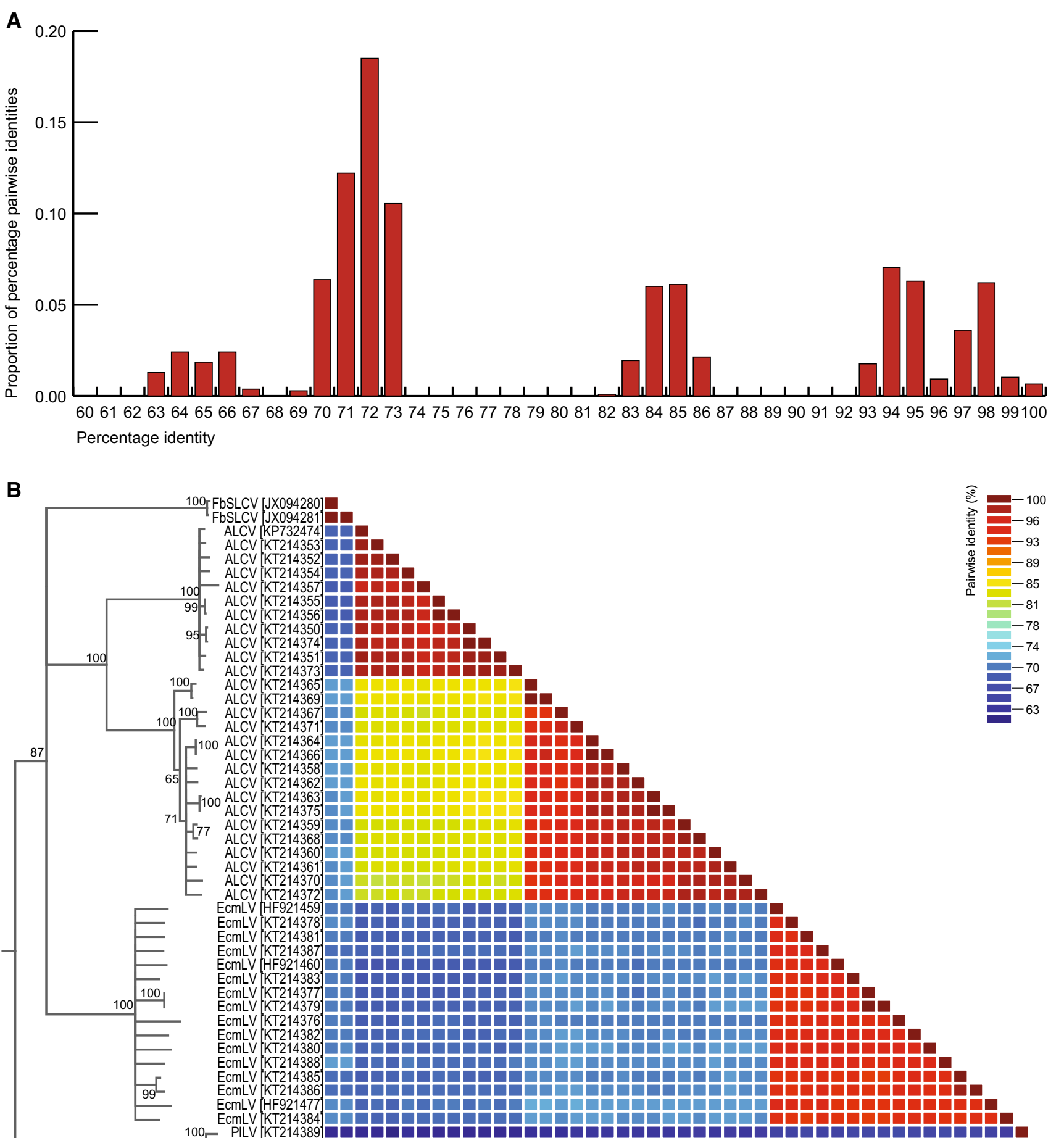

100-FbSLCV [JX094280] FbSLCV [JXX94281]

ALCV [KP732474]

ALCV [KT214353]

ALCV KT214352:

100 ALCV [KT214357,

ALCV VKT214356:-

95 ALCV KT KT214350.

ALCV KKT214351 -

ALCV KTT214373 ALCV KT214365

ALCV [KT214369]

ALCV [KT214367] -

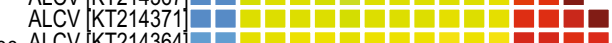

1100 ALCV KT21364

ALCV K 214366 -

ALCV KT 14214358 ,

- ALCV [KT214362]

-100 ALCV VKT214375

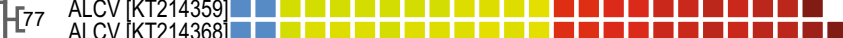

- ALCV $[$ KT214360] D

- ALCV [KT214370]

ALCV IKT214372: EcmLV HF921459

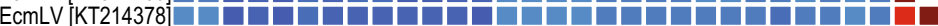

EcmLV 'KT214381

EcmLV KT214387

EcmLV $M F 21438$.

-1
-1

EcmLV KT214383.

EcmLV

EcmLV K 214379 (1)

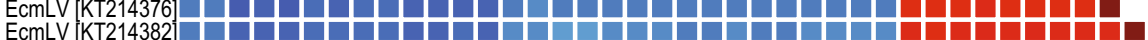

EcmLV KT $214382_{\text {EcmLV }}$,

EcmLV V KT214380:

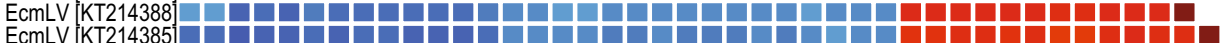

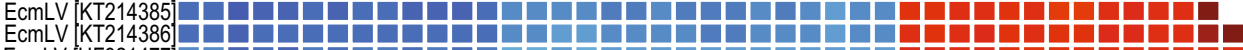

EcmLV [HF921477] - म -

EcmLV $\mid K T 214384$ :

100 C PILV KKT214389j:

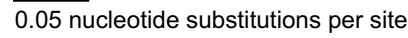

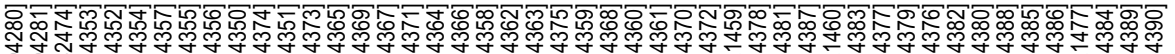

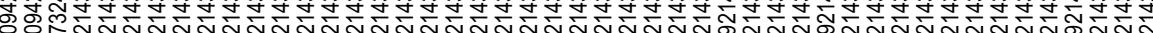

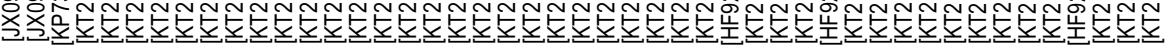

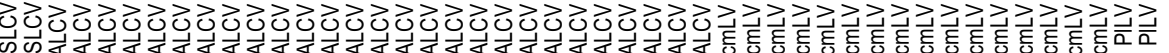

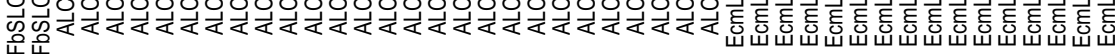

Fig. 4 A. Distribution of pairwise nucleotide sequence identities of 47 known capulavirus genomes. B. Genome-wide pairwise identities determined using SDT v1.2 [27] and a neighbor-joining phylogenetic tree of capulavirus isolates. The tree is rooted with mastrevirus genome sequences (not shown) 
Table 2 Details of virus isolates that have been assigned to the proposed species Grapevine red blotch virus within the genus Grablovirus

\begin{tabular}{|c|c|c|c|c|c|}
\hline Grablovirus & Accession no. & Virus acronym & Isolate & Country & Host \\
\hline \multirow[t]{27}{*}{ Grapevine red blotch virus } & KF147916 & GRBV & NY175 & $\mathrm{USA}^{1}$ & Vitis vinifera \\
\hline & KU564249 & GRBV & NY701 & $\mathrm{USA}^{2}$ & Vitis vinifera cv.Cabernet Sauvignon \\
\hline & JQ901105 & GRBV & JRT[456]17NOV10 & $\mathrm{USA}^{3}$ & Vitis vinifera \\
\hline & KC896623 & GRBV & CF214-1 & USA & Vitis vinifera \\
\hline & KC896625 & GRBV & $\mathrm{Z} 1 \mathrm{~A}-1$ & USA & Vitis vinifera \\
\hline & KF137562 & GRBV & OR1a & $\mathrm{USA}^{4}$ & Vitis vinifera $\mathrm{cv}$. Pinot noir \\
\hline & KF147917 & GRBV & NY135 & $\mathrm{USA}^{5}$ & Vitis vinifera \\
\hline & KF147918 & GRBV & NY137 & $\mathrm{USA}^{5}$ & Vitis vinifera \\
\hline & KF751708 & GRBV & NY147 & $\mathrm{USA}^{3}$ & Vitis vinifera cv. Pinot Noir \\
\hline & KP221559 & GRBV & 1 & USA & Vitis vinifera cv. Early Burgundy \\
\hline & KU564247 & GRBV & NY699 & $\mathrm{USA}^{2}$ & Vitis californica $\mathrm{x}$ Vitis vinifera hybrid \\
\hline & KU564248 & GRBV & NY700 & $\mathrm{USA}^{2}$ & Vitis californica $\mathrm{x}$ Vitis vinifera hybrid \\
\hline & KU564250 & GRBV & NY702 & $\mathrm{USA}^{2}$ & Vitis vinifera $\mathrm{cv}$. Merlot \\
\hline & KU564251 & GRBV & NY703 & $\mathrm{USA}^{2}$ & Vitis vinifera cv. Cabernet franc \\
\hline & KU564252 & GRBV & NY704 & $\mathrm{USA}^{2}$ & Vitis vinifera cv. Cabernet franc \\
\hline & KU564253 & GRBV & NY705 & $\mathrm{USA}^{2}$ & Vitis vinifera cv. Cabernet franc \\
\hline & KU564254 & GRBV & NY913 & $\mathrm{USA}^{2}$ & Vitis californica $\mathrm{x}$ Vitis vinifera hybrid \\
\hline & KU564255 & GRBV & NY921 & $\mathrm{USA}^{2}$ & Vitis vinifera cv. Cabernet franc \\
\hline & KU564256 & GRBV & NY926 & $\mathrm{USA}^{2}$ & Vitis vinifera cv. Cabernet franc \\
\hline & JX559642 & GRBV & $3138-03$ & Canada & Vitis vinifera \\
\hline & КC896624 & GRBV & CS337-1 & USA & Vitis vinifera \\
\hline & KF147915 & GRBV & NY271 & USA & Vitis vinifera \\
\hline & KU821056 & GRBV & SW6 & South Korea & Vitis vinifera \\
\hline & KC427993 & GRBV & GiGV-WA-RS & USA & Vitis vinifera \\
\hline & KC427994 & GRBV & GiGV-WA-DS & USA & Vitis vinifera \\
\hline & KC427995 & GRBV & GiGV-WA-MR & USA & Vitis vinifera $\mathrm{cv}$. Merlot \\
\hline & KC427996 & GRBV & GiGV-WA-CF & USA & Vitis vinifera cv. Cabernet franc \\
\hline
\end{tabular}

US state: ${ }^{1} \mathrm{MD},{ }^{2} \mathrm{CA},{ }^{3} \mathrm{NY},{ }^{4} \mathrm{OR},{ }^{5} \mathrm{PA}$

$\mathrm{CCDaV}$ and MMDaV will need to remain unassigned to a genus until their respective vector species are identified and/or it is confirmed that they form geminate particles.

\section{New geminiviruses identified recently that need to be reviewed by ICTV}

\section{Apple geminivirus and grapevine geminivirus A}

One AGmV complete genome isolated from an apple tree in China (accession no. KM386645) [20] and thirteen GGVA complete genomes isolated from grapevine in China (KX570611), Hungary (KX570618), Israel (KX618694), Japan (KX570610, KX570612, KX570613, KX570615, KX570616, KX570617) and South Korea
(KX570607, KX570609, KX570614) group together, with 94\% bootstrap support (Fig. 2). These viruses isolated from woody plants contain the typical geminivirus-like nanonucleotide motif TAATATTAC and display a distinctly geminivirus-like genome organisation. In addition, these viruses are clearly recombinant, with a begomoviruslike Rep (sharing 59-68\% amino acid sequence identity) and a divergent $\mathrm{CP}$ that is unlike that of any known geminivirus.

The thirteen GGVA sequences share $>97 \%$ identity. The unique $\mathrm{AGmV}$ sequence and the thirteen GGVA sequences share $\sim 63 \%$ genome-wide pairwise identity. The Rep and CP sequences of the AGmV and GGVA isolates share $\sim 60 \%$ and $48 \%$ amino acid sequence identity, respectively, with one another. The Rep proteins are most closely related to those of begomoviruses, curtoviruses, topocuvirus and turncurtoviruses, sharing 50-68\% identity (Fig. 3). Although, based 

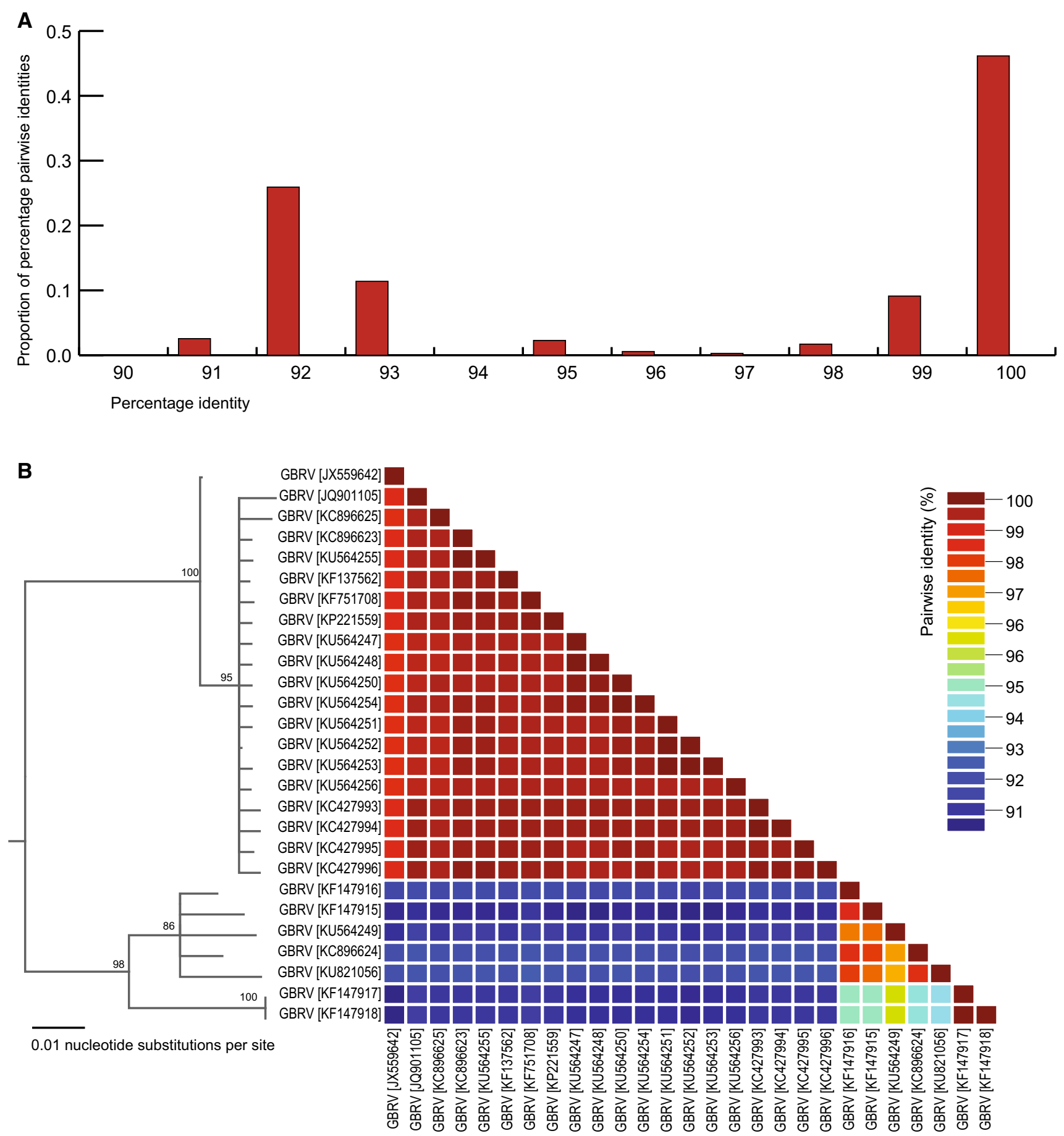

Fig. 5 A. Distribution of pairwise nucleotide sequence identities of 27 grablovirus genomes. B. Genome-wide pairwise identities determined using SDT v1.2 [27] and a neighbor-joining phylogenetic tree

on inferred Rep, AGmV and GGVA branch with begomoviruses, both viruses group separately from all other geminiviruses, with 100\% aLRT branch support (Fig. 2), based on the inferred $\mathrm{CP}$ amino acid sequences.

AGmV and GGVA must also remain unassigned to a genus until the vectors are identified and/or geminate particles are observed. of grablovirus isolates. The tree is rooted with mastrevirus genome sequences (not shown)

\section{Concluding remarks}

The past ten years have seen the establishment of five new geminivirus genera, and the next ten will likely see many more being established as metagenomics-based approaches begin enabling the convenient and cost-effective discovery of viruses in greater numbers from cultivated and non- 
cultivated plant host species [29, 32]. As well as illuminating the actual diversity of geminiviruses and the role played by recombination in their evolutionary history, such approaches also have the potential to elucidate the full range of geminivirus host and vector species. Knowing where geminiviruses are found (especially in non-cultivated hosts where they may cause no obvious disease symptoms) and how they are transmitted will not only enable prediction of which geminiviruses could pose serious threats to agriculture but also provide a detailed view of the actual role of geminiviruses in natural and disturbed terrestrial ecosystems.

Disclaimer This article is based on the taxonomic proposal 2016.014a-iP.A.v2.Geminiviridae_2gen.pdf, which has been considered and approved by the Executive Committee (EC) of the ICTV. A.V. and F.M.Z. are elected members of the ICTV EC. A.V., D.P.M., P.R., J.N.-C., E.M., A.I., R.W.B., R.R.-B. and F.M.Z. are current members of the Geminiviridae study group of the ICTV.

\section{Compliance with ethical standards}

There are no conflicts of interest; the research did not involve human participants or animals. The data used for the analyses in this manuscript are publicly available in GenBank.

\section{References}

1. Adams MJ, Lefkowitz EJ, King AM, Harrach B, Harrison RL, Knowles NJ, Kropinski AM, Krupovic M, Kuhn JH, Mushegian AR, Nibert M, Sabanadzovic S, Sanfacon H, Siddell SG, Simmonds P, Varsani A, Zerbini FM, Gorbalenya AE, Davison AJ (2016) Ratification vote on taxonomic proposals to the International Committee on Taxonomy of Viruses (2016). Arch Virol 161:2921-2949

2. Al Rwahnih M, Alabi OJ, Westrick NM, Golino D, Rowhani A (2017) Description of a novel monopartite geminivirus and its defective subviral genome in grapevine. Phytopathology 107:240-251

3. Arguello-Astorga GR, Ruiz-Medrano R (2001) An iteron-related domain is associated to Motif 1 in the replication proteins of geminiviruses: identification of potential interacting amino acidbase pairs by a comparative approach. Arch Virol 146:1465-1485

4. Bahder BW, Zalom FG, Jayanth M, Sudarshana MR (2016) Phylogeny of geminivirus coat protein sequences and digital PCR aid in identifying Spissistilus festinus as a vector of grapevine red blotch-associated virus. Phytopathology 106:1223-1230

5. Bernardo $P$, Golden $M$, Akram M, Naimuddin Nadarajan N, Fernandez E, Granier M, Rebelo AG, Peterschmitt M, Martin DP, Roumagnac P (2013) Identification and characterisation of a highly divergent geminivirus: evolutionary and taxonomic implications. Virus Res 177:35-45

6. Bernardo P, Muhire B, Francois S, Deshoux M, Hartnady P, Farkas K, Kraberger S, Filloux D, Fernandez E, Galzi S, Ferdinand R, Granier M, Marais A, Monge Blasco P, Candresse T, Escriu F, Varsani A, Harkins GW, Martin DP, Roumagnac P (2016) Molecular characterization and prevalence of two capulaviruses: alfalfa leaf curl virus from France and euphorbia caputmedusae latent virus from South Africa. Virology 493:142-153
7. Bottcher B, Unseld S, Ceulemans H, Russell RB, Jeske H (2004) Geminate structures of African cassava mosaic virus. J Virol 78:6758-6765

8. Bozorgi N, Heydarnejad J, Kamali M, Massumi H (2017) Splicing features in the expression of the complementary-sense genes of Beet curly top Iran virus. Virus Genes. doi:10.1007/ s11262-016-1422-y

9. Briddon RW, Bedford ID, Tsai JH, Markham PG (1996) Analysis of the nucleotide sequence of the treehopper-transmitted geminivirus, tomato pseudo-curly top virus, suggests a recombinant origin. Virology 219:387-394

10. Briddon RW, Heydarnejad J, Khosrowfar F, Massumi H, Martin DP, Varsani A (2010) Turnip curly top virus, a highly divergent geminivirus infecting turnip in Iran. Virus Res 152:169-175

11. Brown JK, Fauquet CM, Briddon RW, Zerbini FM, Moriones E, Navas-Castillo J (2012) Family Geminiviridae. In: King AMQ, Adams MJ, Carstens EB, Lefkowitz EJ (eds) Virus taxonomy. Ninth report of the international committee on taxonomy of viruses. Elsevier Academic Press, London, pp 351-373

12. Brown JK, Zerbini FM, Navas-Castillo J, Moriones E, Ramos-Sobrinho R, Silva JC, Fiallo-Olive E, Briddon RW, Hernandez-Zepeda C, Idris A, Malathi VG, Martin DP, Rivera-Bustamante R, Ueda S, Varsani A (2015) Revision of Begomovirus taxonomy based on pairwise sequence comparisons. Arch Virol 160:1593-1619

13. Candresse T, Filloux D, Muhire B, Julian C, Galzi S, Fort G, Bernardo P, Daugrois JH, Fernandez E, Martin DP, Varsani A, Roumagnac P (2014) Appearances can be deceptive: revealing a hidden viral infection with deep sequencing in a plant quarantine context. PLoS One 9:e102945

14. Darriba D, Taboada GL, Doallo R, Posada D (2011) ProtTest 3: fast selection of best-fit models of protein evolution. Bioinformatics 27:1164-1165

15. Edgar RC (2004) MUSCLE: multiple sequence alignment with high accuracy and high throughput. Nucleic Acids Res 32:1792-1797

16. Guindon S, Dufayard JF, Lefort V, Anisimova M, Hordijk W, Gascuel O (2010) New algorithms and methods to estimate maximum-likelihood phylogenies: assessing the performance of PhyML 3.0. Syst Biol 59:307-321

17. Guo J, Lai XP, Li JX, Yue JQ, Zhang SY, Li YY, Gao JY, Wang ZR, Duan HF, Yang JD (2015) First report on citrus chlorotic dwarf associated virus on lemon in Dehong Prefecture, Yunnan, China. Plant Dis 99:1287

18. Krenz B, Thompson JR, Fuchs M, Perry KL (2012) Complete genome sequence of a new circular DNA virus from grapevine. J Virol 86:7715

19. Krupovic M, Ghabrial SA, Jiang D, Varsani A (2016) Genomoviridae: a new family of widespread single-stranded DNA viruses. Arch Virol 161:2633-2643

20. Liang P, Navarro B, Zhang Z, Wang H, Lu M, Xiao H, Wu Q, Zhou X, Di Serio F, Li S (2015) Identification and characterization of a novel geminivirus with a monopartite genome infecting apple trees. J Gen Virol 96:2411-2420

21. Loconsole G, Saldarelli P, Doddapaneni H, Savino V, Martelli GP, Saponari M (2012) Identification of a single-stranded DNA virus associated with citrus chlorotic dwarf disease, a new member in the family Geminiviridae. Virology 432:162-172

22. Londono A, Riego-Ruiz L, Arguello-Astorga GR (2010) DNAbinding specificity determinants of replication proteins encoded by eukaryotic ssDNA viruses are adjacent to widely separated RCR conserved motifs. Arch Virol 155:1033-1046

23. Lu QY, Wu ZJ, Xia ZS, Xie LH (2015) Complete genome sequence of a novel monopartite geminivirus identified in mulberry (Morus alba L.). Arch Virol 160:2135-2138

24. Ma Y, Navarro B, Zhang Z, Lu M, Zhou X, Chi S, Di Serio F, Li $S$ (2015) Identification and molecular characterization of a novel 
monopartite geminivirus associated with mulberry mosaic dwarf disease. J Gen Virol 96:2421-2434

25. Moffat AS (1999) Plant pathology-geminiviruses emerge as serious crop threat. Science 286:1835

26. Muhire B, Martin DP, Brown JK, Navas-Castillo J, Moriones E, Zerbini FM, Rivera-Bustamante R, Malathi VG, Briddon RW, Varsani A (2013) A genome-wide pairwise-identity-based proposal for the classification of viruses in the genus Mastrevirus (family Geminiviridae). Arch Virol 158:1411-1424

27. Muhire BM, Varsani A, Martin DP (2014) SDT: a virus classification tool based on pairwise sequence alignment and identity calculation. PLoS One 9:e108277

28. Poojari S, Alabi OJ, Fofanov VY, Naidu RA (2013) A leafhopper-transmissible DNA virus with novel evolutionary lineage in the family geminiviridae implicated in grapevine redleaf disease by next-generation sequencing. PLoS One 8:e64194

29. Roossinck MJ, Martin DP, Roumagnac P (2015) Plant virus metagenomics: advances in virus discovery. Phytopathology 105:716-727

30. Roumagnac P, Granier M, Bernardo P, Deshoux M, Ferdinand R, Galzi S, Fernandez E, Julian C, Abt I, Filloux D, Mesleard F, Varsani A, Blanc S, Martin DP, Peterschmitt M (2015) Alfalfa leaf curl virus: an aphid-transmitted geminivirus. J Virol 89:9683-9688

31. Rybicki EP (1994) A phylogenetic and evolutionary justification for three genera of Geminiviridae. Arch Virol 139:49-77

32. Simmonds P, Adams MJ, Benko M, Breitbart M, Brister JR, Carstens EB, Davison AJ, Delwart E, Gorbalenya AE, Harrach B, Hull R, King AMQ, Koonin EV, Krupovic M, Kuhn JH, Lefkowitz EJ, Nibert ML, Orton R, Roossinck MJ, Sabanadzovic S, Sullivan MB, Suttle CA, Tesh RB, van der Vlugt RA, Varsani A, Zerbini FM (2017) Consensus statement: virus taxonomy in the age of metagenomics. Nat Rev Microbiol. doi:10.1038/nrmi cro. 2016.1177
33. Stanley J, Markham PG, Callis RJ, Pinner MS (1986) The nucleotide sequence of an infectious clone of the geminivirus beet curly top virus. EMBO J 5:1761-1767

34. Stover BC, Muller KF (2010) TreeGraph 2: combining and visualizing evidence from different phylogenetic analyses. BMC Bioinform 11:7

35. Sudarshana MR, Perry KL, Fuchs MF (2015) Grapevine red blotch-associated virus, an emerging threat to the grapevine industry. Phytopathology 105:1026-1032

36. Susi H, Laine A-L, Filloux D, Kraberger S, Farkas K, Bernardo P, Frilander MJ, Martin DP, Varsani A, Roumagnac P (2017) Genome sequences of a capulavirus infecting Plantago lanceolata in the Aland archipelago of Finland. Arch Virol (in press)

37. Varsani A, Shepherd DN, Dent K, Monjane AL, Rybicki EP, Martin DP (2009) A highly divergent South African geminivirus species illuminates the ancient evolutionary history of this family. Virol J 6:36

38. Varsani A, Martin DP, Navas-Castillo J, Moriones E, HernandezZepeda C, Idris A, Murilo Zerbini F, Brown JK (2014) Revisiting the classification of curtoviruses based on genome-wide pairwise identity. Arch Virol 159:1873-1882

39. Varsani A, Navas-Castillo J, Moriones E, Hernandez-Zepeda C, Idris A, Brown JK, Murilo Zerbini F, Martin DP (2014) Establishment of three new genera in the family Geminiviridae: Becurtovirus, Eragrovirus and Turncurtovirus. Arch Virol 159:2193-2203

40. Wright EA, Heckel T, Groenendijk J, Davies JW, Boulton MI (1997) Splicing features in maize streak virus virion- and complementary-sense gene expression. Plant J 12:1285-1297

41. Zhang W, Olson NH, Baker TS, Faulkner L, Agbandje-McKenna M, Boulton MI, Davies JW, McKenna R (2001) Structure of the maize streak virus geminate particle. Virology 279:471-477 